\title{
O SUJEITO E A COLETIVIDADE' UM CAMINHO TRANSDIALÓGICO NA SAÚDE COLETIVA
}

\author{
Silvani Botlender Severo \\ Nedio Seminotti ${ }^{3}$
}

Resumo: Este artigo apresenta os resultados e reflexões de uma pesquisa que objetivou compreender aspectos dificultadores e facilitadores no processo de ativação da integralidade na ação transdisciplinar em uma equipe multiprofissional na saúde coletiva. Esse percurso transdialógico usou como fundamentos a teoria da complexidade e os princípios do método de Edgar Morin e a lógica transdisciplinar proposta por Basarab Nicolescu, tendo como organizador central a interdependência entre Sujeito e Coletividade na construção da política pública em saúde. A pesquisa trouxe o desvelamento da coexistência de duas lógicas que organizam os processos de trabalho na saúde: a lógica da doença/lógica disciplinar e a lógica da integralidade/lógica transdisciplinar.

Palavras-chave: Saúde pública. Transdisciplinaridade. Comportamento coletivo. Reforma psiquiátrica. Profissionais da saúde.

\section{Política pública em saúde e a integralidade da atenção}

Esta é a transcrição e tradução de um percurso investigativo que exercitou uma relação complexa com o trabalhador em saúde a partir da noção de Sujeito

1 Este artigo é parte integrante da dissertação de mestrado da primeira autora, intitulada A transdialógica na Integralidade da Atenção a Saúde: a Organização da Saúde e a Saúde da Organização, Financiada pela CAPES.

2 Pós-Graduanda no curso de Pós-Graduação em Psicologia, Pontifícia Universidade Católica do Rio Grande do Sul. Email: silvani.severo@terra.com.br

3 Docente do Programa de Pós-Graduação em Psicologia, Faculdade de Psicologia Pontifícia Universidade Católica do Rio Grande do Sul.E-mail: nedio.seminotti@pucrs.br 
de Edgar Morin (2002a). Alicerçamo-nos na interconexão entre os sete princípios do Método (Morin, 2002a, p. 92) e a lógica transdisciplinar (Nicolescu, 2001, 2005).

Os questionamentos geradores desta pesquisa advieram das experiências profissionais da autora em psicologia na política pública de saúde como trabalhadora e gestora em saúde mental, compreendidas desde as lógicas de um sistema complexo (Morin, 2000, 2001, 2002a, 2002b, 2003, 2005a, 2005b; Moraes, 2004; Vasconcellos, 2002).

Circulamos entre teoria e prática para compreender o processo de ativação do princípio da integralidade (art. 196, II, Constituição Federal de 1988; art. 7, II da Lei 8080/1990 - Sistema Único de Saúde - SUS) na ação transdisciplinar das equipes multiprofissionais na saúde coletiva (Campos, 2000; L'Abbate, 2003; Paim \& Almeida Filho, 1998).O organizador central deste estudo são as discussões acerca da interdependência entre Sujeito e Coletividade na construção da política pública em saúde.

A organização do trabalho na saúde através das equipes multiprofissionais é uma estratégia para minimizar, nesse campo, os efeitos negativos do intenso processo de especialização, que tem caracterizado diversas práticas na contemporaneidade (Campos, 1997a, 1997b, 1998; Iribarry, 2003; Peduzzi, 1998, 2001; Peduzzi \& Anselmi, 2002).

A política pública de saúde no Brasil, decorrência do Movimento Sanitarista e da Reforma Sanitária (Ceccim, 2005; Feuerwerker, 2005; Gallo, Luchesi, Machado Filho, \& Ribeiro, 1988; Lana \& Gomes, 1996; Paim \& Teixeira, 2006), reorienta e enfatiza modelos de atenção integral nas ações dos trabalhadores. O SUS presentifica-se na interconexão e interdependência entre as diretrizes e ações de cada esfera de governo (federal, estadual e municipal).É um sistema multidimensional que estabelece conexões com outras políticas públicas, integrando a subjetividade do trabalhador em saúde com aspectos técnico-políticos de formação profissional, modelos de gestão, planejamento, financiamento e ações intersetoriais (Ayres, 2001; Campos, 1997a, 1997b, 1998; Cecílio, 1997a, 1997b; Fagundes, 2003, 2006; Minayo, 2001; Sá, 2001; Schraiber \& Machado, 1997; Testa, 2004).

$\mathrm{Na}$ ativação do princípio da integralidade, existe uma situação paradoxal no campo da saúde. Há contradições no cotidiano dos serviços, principalmente no que tange aos trabalhos realizados por equipes multiprofissionais, diante da exigência de processos inter/ transdisciplinares. Os trabalhadores, na relação interprofissional, acessam suas distintas formações disciplinares na realização das tarefas e encontram dificuldades na sua prática coletiva. É necessária a integração de diferentes paradigmas, conceitos e lógicas sobre o 
binômio saúde-doença (Coelho \& Almeida Filho, 2002; Schraiber \& Machado, 1997; Schraiber, Peduzzi, Nemes, Castanheira, \& Kon, 1999).

Diversos autores estudam a integralidade como dispositivo de mudança do modelo assistencial para a implantação de práticas eficazes (Cecílio, 2001; Fagundes, 2003, 2006; Pinheiro \& Mattos, 2004; Pinheiro \& Luz, 2003) e como tecnologia de cuidado relevante para a implantação e consolidação do SUS. A integralidade é compreendida como a organização do fazer disciplinar/profissional, do processo de trabalho nas equipes e nos serviços e da política pública em saúde (Mattos, 2001, 2004).

Diante das dificuldades enfrentadas pelos trabalhadores na reorientação do modelo assistencial da doença em direção ao modelo de atenção integral (Campos, 1997a, 1997b; Ceccim, 2005; Merhy, 1997; Pitta, 2001), emerge a necessidade da reflexão sobre o cotidiano e os processos de trabalho. Por meio do processo reflexivo, alguns trabalhadores podem romper as barreiras de suas lógicas e abrir-se para a invenção de estratégias e dispositivos criativos (L'Abbate, 1997; Ribeiro \& Motta, 1996).

No processo reflexivo intersubjetivo entre os trabalhadores e trabalhadores/usuários, pode ocorrer o diálogo entre múltiplos saberes (especialista, técnico, administrativo, do usuário). Ao mesmo tempo, esses saberes "co-operam" com relações lineares, com a dominância de um saber sobre outros, ensejando práticas autoritárias. A interação entre distintos paradigmas que atravessam a rede de significados de cada Sujeito contrapõe-se à dificuldade de diálogos e processos inter/ transdisciplinares.

Assim, entendemos a política pública como propositora de mudanças paradigmáticas por meio dos processos intersubjetivos e da compreensão dos sistemas complexos. Concebem-se movimentos recursivos entre processos de subjetivação e transformações socioculturais que podem revelar os elos entre o Sujeito e a Coletividade.

\section{Complexidade e a integração dos saberes}

$\mathrm{O}$ trabalho em equipes possibilita processos interdisciplinares e transdisciplinares. Interdisciplinarizar (Azevedo e Souza, Azevedo e Souza, \& Marques, 2006; D’Ambrosio, 1997; Fazenda, 2002; Jantsch \& Bianchetti, 2002; Iribarry, 2003; Japiassu, 1976; Nicolescu, 2001, 2005; Pombo, 2005; Sommerman, 2006) pode compreender-se como uma forma de interação entre duas ou mais disciplinas, e diz respeito, geralmente, à transferência de métodos de uma disciplina a outra.

Por outro lado, Pombo (2005) concebe as diferentes formas de integração disciplinar como um processo progressivo que inicia na multi/ 
pluridisciplinaridade, que é o pôr em conjunto, passando para a interdisciplinaridade, que é a articulação entre os saberes, até chegar à transdisciplinaridade, que pressupõe um ponto de fusão, de unificação dos saberes. Já Nicolescu (2005) propõe o conceito de transdisciplina como uma lógica distinta da lógica clássica, conceito este com o qual nos identificamos.

\section{Lógica clássica}

$O$ axioma da identidade: $\mathrm{A}$ é $\mathrm{A}$

O axioma da não-contradição:

A não é não-A

O axioma do terceiro excluído: não existe um terceiro termo que é ao mesmo tempo A e não-A

\section{Lógica transdisciplinar}

O axioma da identidade: $\mathrm{A}$ é $\mathrm{A}$

O axioma da não-contradição:

A não é não-A

O axioma do TerceiroTermo Incluído $(T)$ :

A, não-A e T no mesmo momento do tempo

Tabela 3: Comparação entre lógica clássica e lógica transdisciplinar.

A lógica transdisciplinar assemelha-se à lógica clássica nos dois primeiros axiomas, mas diferencia-se no Terceiro Termo Incluído (T). Para Lupasco, formulador dessa lógica (Badescu \& Nicolescu, 2001), o T pode ser a dialógica, e, para Nicolescu (2005), pode ser o Sujeito.Trata-se de um Sujeito que está aberto ao diálogo, pelo reconhecimento da convivência de mais de um nível de realidade, em que não há uma hierarquia piramidal expressa na relação de poder de um sobre os outros. A hierarquia está vinculada às organizações do processo e às emergências na circularidade entre o fazer individual e o coletivo.

Um nível de realidade é o "conjunto de sistemas invariantes sob a ação de um número de leis gerais" (Nicolescu, 2001, p. 29), sendo que realidade, para esse autor, é "aquilo que resiste às nossas experiências, representações, descrições, imagens ou formalizações matemáticas" (p. 28).

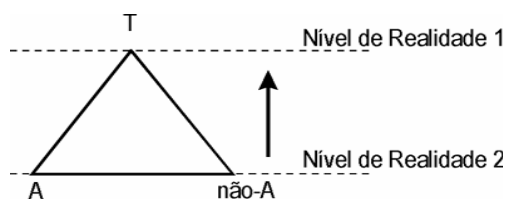

Fig. 1: Representação dos níveis de realidade. Fonte: Nicolescu, 2002, p. 51.

Entendemos a transdisciplinaridade como metodologia de pesquisa embasada em três pilares (Nicolescu, 2001, 2005): os diferentes níveis de realidade do objeto e níveis de percepção do Sujeito; a lógica do Ter- 
ceiro Termo Incluído e a complexidade. A lógica transdisciplinar está na gênese deste estudo, e operou na lógica da pesquisadora numa relação recursiva com o objeto pesquisado. Os diferentes níveis de realidade e níveis de percepção são computados a partir das lógicas dos participantes e da pesquisadora em processos de auto-eco-organização.

O Sujeito e a equipe multiprofissional

O sujeito trabalhador em saúde, na sua relação multiprofissional de trabalho, depara-se com situações complexas que exigem sua entrega à multiplicidade de lógicas e, ao mesmo tempo, que cada indivíduo se posicione no centro de seu mundo: que ocupe seu espaço egocêntrico (Morin, 2002a). Dessa forma, a intersubjetividade pode ser reconhecida e integrada na alteridade como um elemento do sistema e como estratégia na realização das tarefas coletivas - como, por exemplo, pela mediação reflexiva (Barker \& Dominici, 1999), a qual, na produção subjetiva entre os trabalhadores, gera novas estratégias e novas invenções. Estratégia que é aberta e reorganiza o caos, que comporta a variabilidade, encontrando recursos e desvios, operando regressos e afastamentos, enfrentando o imprevisto (Morin, 2002b).

Nesse campo da saúde coletiva, que é marcado por conflitos de natureza epistemológica e de relações de poder entre os trabalhadores e suas respectivas lógicas (Paim \& Almeida Filho, 2000), o Sujeito, como um sistema aberto/fechado no exercício entre as fronteiras disciplinares, com rigor científico e tolerância, pode interdisciplinarizar, realizar ações intersetoriais e trabalhos em equipes.

É nas equipes multiprofissionais, no processo e na organização desse pequeno grupo, em que todos se conhecem e reconhecem em seus modos de existência e nas diferenças e semelhanças que há na intersubjetividade entre eles (Seminotti, 2000; Seminotti, Borges, \& Cruz, 2004), que a experiência reflexiva propicia o reconhecimento e a legitimação das lógicas singulares, podendo viabilizar a integração dos saberes.

Esse trabalho em grupo no campo da saúde coletiva é justificadamente transdisciplinar (Almeida Filho, 1997; Passos \& Barros, 2000). Exige um pensamento do contexto e do complexo (Morin, 2002a). "Eu sou eu", princípio logístico de identidade em que o Sujeito em seu "ego é potencialmente outro, sendo ao mesmo tempo ele mesmo" ( $p$. 123). Sujeito produto e produtor (auto-eco-organizado) que constrói sua autonomia nas relações de dependência, pois sua liberdade está sujeitada ao outro e à coletividade (Morin, 2002a). Sujeito capaz de objetivar-se sem anular sua dimensão subjetiva. Distinção necessária no cuidado de si e ao outro, possibilitada pela permanência da autoreferência ligada ao "Eu". 
Assim, tem-se um Sujeito ( $T$ ), que oportuniza as emergências na inclusão/pertença ao sistema complexo da saúde - na política, nos serviços, nas equipes e no fazer profissional. Um Sujeito (T) aberto à intersubjetividade. Na interdependência hologramática, onde a parte está no todo e o todo inscrito nas partes, são produzidas novas lógicas de ação que possibilitam o trabalho transdisciplinar na equipe.

O Sujeito $(T)$ organiza o sistema pela dialógica entre os pares de contraditórios numa triangulação, no mesmo momento do tempo (A, nãoA e T): Sujeito/coletividade/T; saúde/doença/T; público/privado/T; manicomiais/antimanicomiais/T, integrando-os na unidualidade como complementares (Morin, 2002a).

\section{O CAPS na Reforma Psiquiátrica - o contexto político/social e local}

Os Centros de Atenção Psicossocial - CAPS (Portarias 336/2002 e 189/ 2002) - são serviços públicos substitutivos ao modelo hospitalocêntrico. A proposta de trabalho é o atendimento intensivo e humanizado ao portador de sofrimento psíquico grave e a constituição de redes cuidadoras (Ministério da Saúde, 2004). Opõe-se ao sistema de isolamento e institucionalização do "louco".É um serviço em que os trabalhadores podem exercer o acolhimento, a escuta e a significação de uma relação com o Sujeito usuário na perspectiva da alteridade.

Nesse universo em transformação a partir da política de Reforma Psiquiátrica, que tem diretriz antimanicomial, há processos de ordem/desordem, avanços/retrocessos e novas organizações. Os trabalhadores nos CAPS realizam projetos e intervenções, muitas vezes, sem o dimensionamento do sistema complexo do qual fazem parte. Sentimentos de impotência e adoecimentos são gerados pelas frustrações de uma prática com fins teleológicos quando trabalham na direção da cura/saúde mental, compreendida como organização de uma desordem psíquica e ajustamento ao padrão estereotipado de normalidade. Em contrapartida, apesar dos movimentos de contra-reforma, as lógicas antimanicomiais produzem novos paradigmas nos processos de subjetivação de trabalhadores e usuários e na sociedade.

A equipe multiprofissional que tomamos por objeto de pesquisa pertence a um CAPS localizado em município da região metropolitana do estado do Rio Grande do Sul, e é composta por: psiquiatra, psicóloga, assistente social, terapeuta ocupacional, enfermeira, fonoaudióloga e técnica de enfermagem - seis profissionais de nível superior e um funcionário de nível médio. Participou também da pesquisa uma psicóloga que coordena a área de saúde mental do município. Os trabalhadores da área administrativa, da portaria e da limpeza atendiam outros dois serviços de saúde mental que se localizavam no mesmo espaço físico. O CAPS faz 
parte de uma rede que inclui um hospital geral, a atenção básica e os serviços de saúde mental: um "ambulatório" em saúde mental, o CAPS e um centro de atendimento à criança e ao adolescente.

Caminho transdialógico - um método recursivo e auto-ecoorganizador

O delineamento da pesquisa propiciou a análise dos processos interativos e interdependentes entre os participantes, as concepções e paradigmas que percorrem o imaginário simbólico dessas relações entre/através/além dos Sujeitos, dos Sujeitos-trabalho, dos Sujeitos-políticas públicas, juntamente com os aspectos facilitadores e/ou dificultadores dessas práticas. Um olhar transversalizado sobre os processos recursivos, de retro-alimentação e auto-eco-organização que caracterizam o fenômeno nas relações de interdependência com o contexto.

Descrevemos abaixo os princípios do método (Morin, 2002a, pp.9396) para auxiliar a compreensão/explicação dessa tessitura:

- princípio sistêmico ou organizacional, que liga o conhecimento das partes ao conhecimento do todo;

- princípio “hologrâmico",em que a parte está no todo, assim como o todo está inscrito nas partes;

- princípio do circuito retroativo, em que a causa age sobre o efeito e o efeito age sobre a causa, modificando-a, gerando um novo efeito (retroação auto-reguladora);

- princípio do circuito recursivo, em que os produtos e os efeitos são eles mesmos produtores e causadores do que os produz;

- princípio da autonomia/dependência entre Sujeito/indivíduo/ambiente (auto-eco-organização);

- princípio dialógico - união entre ordem e desordem gera novas organizações; idéias e ações antagônicas, complementares ou concorrentes formam novas sínteses;

- princípio da reintrodução do conhecimento em todo conhecimento, revelando o problema cognitivo central: da percepção à teoria científica, todo conhecimento é uma reconstrução/tradução feita por uma mente/cérebro em uma cultura e época determinadas. 
$\mathrm{Na}$ recursividade entre teoria/prática, conhecimento/desconhecimento do objeto pesquisado, a palavra organização distinguiu-se e sustentou a produção de conhecimento a partir de um Sujeito pesquisadora auto-eco-organizada, que estabeleceu movimentos de retroações, recursividades e novas organizações com o objeto pesquisado, em consonância com a teoria sistêmica.

Para Morin (2005a), as diversas definições de sistemas do século XVII incluíam a idéia de que uma unidade global é constituída pela interrelação entre as partes. Entretanto, acrescenta o autor que, além da totalidade organizada e da interconexão das partes em função de seu lugar nesse conjunto, é preciso ligar totalidade à inter-relação pela idéia de organização. "A ordem era a noção que, aniquilando todas as outras, tinha aniquilado também a idéia de organização" (p. 123). Resgata-se, então, o aspecto dinâmico dos sistemas.

Assim, há uma lógica organizadora que perpassa nossas discussões e que organiza a relação sistêmica da pesquisadora enquanto observador/ator/conceptor/observado com o objeto pesquisado e da circularidade entre outros papéis, como trabalhadora e gestora em saúde: o Sujeito exerce o seu fazer a partir de suas lógicas, de um saber disciplinar, em um processo individual e/ou grupal, reconstrói lógicas no processo interdisciplinar das equipes - lógicas que, recursivamente, podem se transformar em paradigmas. Estes são constituídos por um certo tipo de relação lógica extremamente forte entre noções mestras, noções-chave e princípios-chave (Morin, 2003).

Ratificando nosso exercício de um pensamento complexo, o delineamento de pesquisa a partir dos sete princípios do Método proposto por Edgar Morin (2002a) veio pelo exercício no "conhecimento do conhecimento" e por um caminho metodológico através da atividade pensante. Um percurso na integração de um Eu-Sujeito-pesquisadora: um caminho transdialógico. O Sujeito $(T)$ triangula o diálogo, como diz o prefixo "trans": entre, através e além de múltiplas lógicas. "O objetivo do método, aqui, é ajudar a pensar por si mesmo para responder ao desafio da complexidade dos problemas" (Morin, 2005b, p. 36).

Propomos a transdialógica, que é a inclusão do Sujeito (T) na dialógica entre os pares de antagônicos, contraditórios e concorrentes. O exercício da dialógica encontra dificuldades quando os Sujeitos dialogam a partir da lógica clássica, do terceiro excluído e dessa separabilidade entre Sujeito e objeto. A intersubjetividade desde a transdialógica possibilita a integração dos saberes pelo Sujeito $(T)$ na escuta das lógicas singulares entre os trabalhadores e trabalhadores/usuários. 
Traduzindo a lógica da pesquisadora

A coleta dos dados foi efetuada por meio da observação participante (Anguera et al., 1995) no espaço físico do CAPS e em atividades externas realizadas com os trabalhadores. $O$ foco principal recaiu sobre quatro reuniões da equipe multiprofissional, que foram gravadas. Na última, promoveu-se um processo reflexivo com os trabalhadores, proposto pela pesquisadora. Além das reuniões, a pesquisadora participou de visitas domiciliares e contato com o Programa Saúde da Família, de assembléia de usuários, de reunião da Associação de Usuários, de reunião geral da saúde mental e de atividades cotidianas, como: atendimentos, oficinas, almoços e conversas no cafezinho. Também foi utilizado o registro em diário de campo e a consulta a documentos (projetos, textos, correspondências e atas das reuniões).

No processo reflexivo, traduziu-se à equipe multiprofissional a lógica da pesquisadora acerca de um espaço transdialógico entre os participantes. Contextualizamos a integralidade na política pública de saúde remetida à idéia sistêmica e comentamos a proposta de organização dos CAPS em modalidades de atendimento - intensivo, semi-intensivo e nãointensivo - e seus respectivos financiamentos. Foi feita uma pergunta aos trabalhadores que emergiu das observações sobre o seu fazer no serviço, unida ao objetivo de compreender a ativação da integralidade: como acontece a organização do processo de trabalho neste CAPS?

A análise dos dados traduz os processos interdependentes entre os Sujeitos participantes da pesquisa, a pesquisadora e o contexto. Segue a organização dos dados para contemplar essa tradução.

$1^{\circ}$ passo: transcrição das gravações das quatro reuniões

$2^{\circ}$ passo: distinção de quatro sistemas

$\mathrm{Na}$ análise dos dados, percebemos que existem, no sistema complexo da saúde, sistemas que dialogam a partir de um conjunto de saberes e lógicas e em função de seus lugares nessa totalidade. Nele, o sistema Sujeito ocupa um lugar central na relação de interdependência com outros sistemas coletivos. É um sistema multidimensional e multirreferencial, que institui a auto-eco-organização a partir de lógicas que geram processos de trabalho, movimentos e novas organizações - ou seja, um Sujeito que institui dinâmicas no sistema. Então, discutiremos quatro sistemas compreendidos e explicados pela pesquisadora: 
- Sistema Sujeito/Alteridade: na dinâmica do fazer profissional/disciplinar, representa a instância subjetiva de cada trabalhador em saúde na sua tarefa de trabalho. Uma tarefa realizada em direção a outro Sujeito, na equipe e na atenção ao Sujeito usuário."Os Sujeitos se auto-organizam em relação a outros Sujeitos" (Morin, 2002a, p. 78).

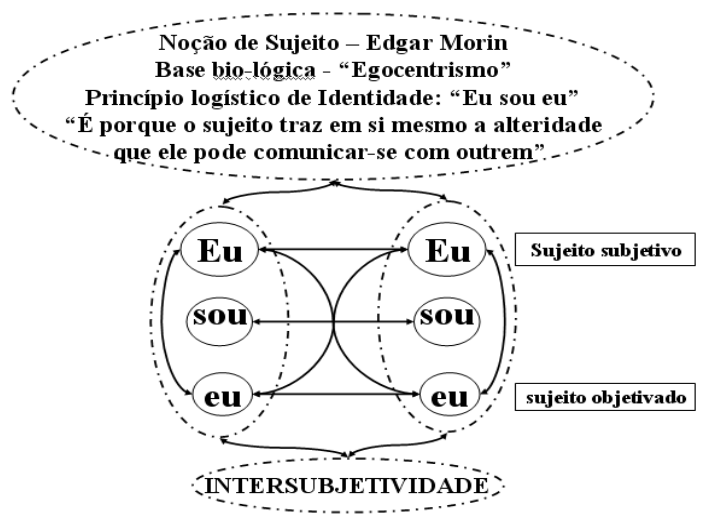

Fig. 2: Sistema sujeito/alteridade.

- Sistema Sujeito/Outro - Equipe: na dinâmica do fazer profissional/ disciplinar, representa a intersubjetividade no processo interdisciplinar. Remete à inter-relação entre o fazer profissional/disciplinar na interação com os outros trabalhadores constituintes da equipe e suas distintas profissões/disciplinas. Traduz o processo interdisciplinar de um fazer profissional sujeitado pela inter-relação entre os diferentes níveis de percepção do Sujeito e de realidade do objeto e pela transversalização entre teoria e a prática.

- Sistema Sujeito/Nós - Serviço: na dinâmica do fazer profissional/ disciplinar, que, além de intersubjetivo e interdisciplinar, também é intersetorial. Existe a relação com outros profissionais/atores de outros sistemas governamentais e não governamentais inseridos em outras políticas públicas, como educação, assistência social, planejamento, habitação e cultura. O sistema Sujeito articula-se com o sistema Serviço e referencia o pensamento ao conjunto representado por pessoas, grupos, estrutura física e culturas institucionais.

- Sistema Sujeito/Coletividade - Política Pública:na dinâmica do fazer profissional/disciplinar, na intersubjetividade, na interdisciplinaridade, na intersetorialidade e na coletividade. Política pública em saúde quando compreendida como um sistema permeável em movimentos de aber- 
tura e fechamento. O Sujeito está na coletividade, assim como a coletividade encontra-se representada no Sujeito, e há uma transversalidade na interdependência dos sistemas entre si. Conforme o esquema abaixo, compreendemos que a política pública somente se concretiza através de Sujeitos $(T)$ que instauram as instituições na conjugação circular entre conhecimentos e ação. Entre o subjetivo e o político, há uma recursividade nos modos de produção dos sistemas e modos de subjetivação. O sistema Sujeito é contextualizado na cultura.

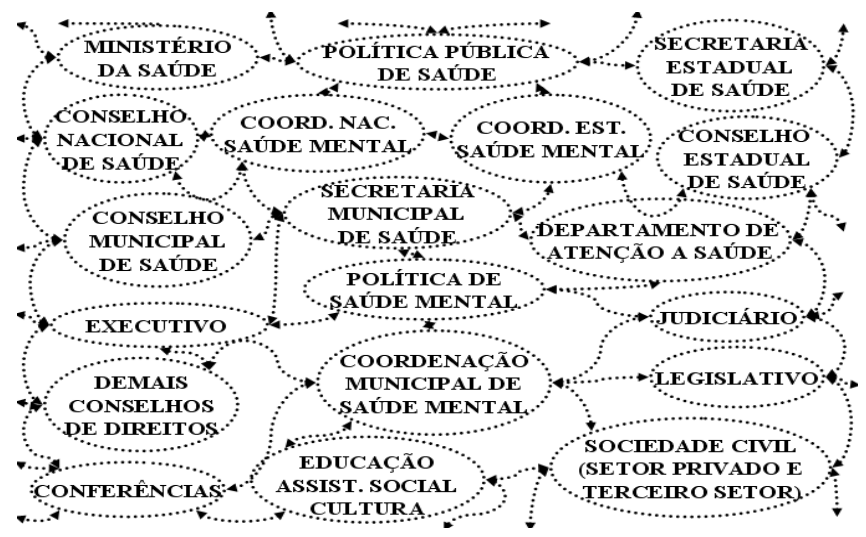

Fig. 3: Esquema ilustrativo de Sistema Sujeito/Coletividade - Política Pública.

O sistema Sujeito/Alteridade é concebido no centro da reorganização e reorientação do modelo de atenção à saúde, compreendendo-o, assim, como parte constituinte, produto e produtor do sistema de saúde e da política pública. É um Sujeito sócio-histórico que participa da produção em saúde coletiva e constrói condições para ela.

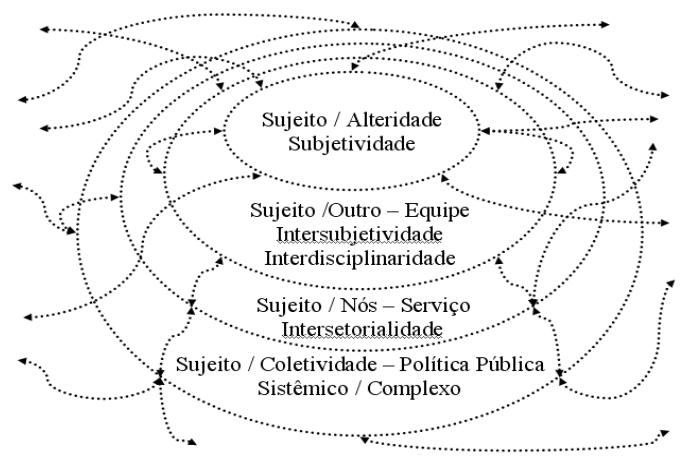

Fig. 4: Dinâmica recursiva e organizacional. 
$3^{\circ}$ passo: análise dos dados

Na tradução dos dados, a pesquisadora oscilou entre a lógica linear (temporal e teleológica) e a transdialógica. Na linear, a interpretação pressupõe a sucessão no tempo a partir da tríade hegeliana - tese, antítese e síntese. Na transdialógica, tem-se o"aqui e agora" da pesquisadora com o objeto pesquisado. Ocorre uma circularidade retroativa do observador na sua observação, incluindo-se enquanto observado na sua concepção. Há também o reconhecimento dos Sujeitos participantes enquanto Sujeitos $(T)$ e da emergência da inventividade e da criatividade de todos (Morin, 2003).

A análise compreendeu quatro níveis de realidade/percepção no processo de organização dos dados.

- $1^{\circ}$ nível de realidade/percepção - primeira distinção: inter-relações - princípio da recursão organizacional

Nas transcrições das reuniões, traduzimos nas falas dos trabalhadores a distinção entre os quatro sistemas: sistema Sujeito/Alteridade; sistema Sujeito/Outro - Equipe; sistema Sujeito/Nós - Serviço; sistema Sujeito/Coletividade - Política Pública. Neste primeiro nível, operacionalizamos a distinção das características que pertencem a cada sistema pela diferença com os demais em uma dinâmica recursiva e organizacional. Após essa primeira distinção, na sistematização das conversações em tabela de cada um dos sistemas, observou-se que o sistema Sujeito/Alteridade ficou sem anotações.

Percebemos, então, que o sistema Sujeito/Alteridade não pode ser separado dos outros. Emerge a contradição na lógica da pesquisadora, que, num primeiro momento, foi percebida pela racionalização como erro por separar esse sistema. Para Morin (2002c), a racionalização é a doença da razão e é fechada; já a racionalidade é aberta. Num segundo momento, percebe-se pela racionalidade que somente a partir da distinção desse sistema em relação aos outros é que houve possibilidade de unificação. Aqui aparece a diferença entre o paradigma cartesiano/mecanicista, que separa e reduz, e o paradigma complexo, que distingue e une. Abriram-se, assim, espaços para a criação de estratégias e movimentos de auto-eco-organização por uma ruptura lógica: desde uma computação cognitiva (Morin, 2002a), que acreditava separar o sistema Sujeito do objeto no processo de conhecimento, para uma nova organização, que pressupõe modificações no imaginário da pesquisadora.

Em um primeiro momento, a lógica clássica/cartesiana opera na subjetividade da pesquisadora e, após "uma emergência reflexiva, que permite o retorno da mente a si mesma, em circuito", emerge a qualidade do Sujeito, que é a consciência para Morin (2002a, p. 126). É pela reflexão na 
ação que a pesquisadora se coloca em outro nível de realidade e se inclui como um Sujeito $(T)$ na interação com os dados. Dialogicamente, também se inclui a percepção dos participantes como Sujeitos $(T)$.

- $2^{\circ}$ nível de realidade/percepção - segunda distinção: interações entre os sistemas a partir do sistema Sujeito - princípio dialógico

Nesta segunda distinção, que é decorrência da primeira, há um movimento de reorganização na produção do conhecimento por um pensamento compreensivo/explicativo dos dados a interpretar.

Pela observação, no mesmo momento do tempo (Nicolescu, 2001, 2005), da pesquisadora Sujeito ( $T$ ) com suas percepções na identificação com os participantes como trabalhadora em saúde/gestora (A é A) e na sua distinção em relação aos mesmos no sistema pelo papel de pesquisadora (A não é não-A), ocorreu uma reorganização metodológica da pesquisa.É a pesquisadora Sujeito $(T)$ que organiza a ação.É na interação entre as partes dos sistemas e entre os próprios sistemas que ocorrem novas produções e emergências. Essas emergências são as qualidades do sistema (Morin, 2005b).

Pelas emergências na observação das ações dos participantes da pesquisa, desvelou-se a compreensão/explicação das práticas pelas lógicas subjacentes a elas. Surgiram dificuldades na tradução dos dados pela interpretação analítica e/ou dialógica, revelando-se a abertura para a focalização nas recursividades entre Sujeito e suas organizações, tanto no fazer individual como na equipe, no serviço e na política pública. Essa abertura preexistia na escolha do delineamento da pesquisa.

O caminho transdialógico produziu e foi produzido pela subjetividade da pesquisadora diante desses impasses metodológicos e dessa abertura cognitiva para o desconhecido. Ocorreu outra ruptura na lógica da pesquisadora quando se desvelou na ação a inseparabilidade dinâmica entre as lógicas cartesiana e dialógica. Pensamos que, atualmente, as dificuldades dos Sujeitos em operar dialogicamente a partir de conhecimentos estruturados numa lógica cartesiana podem advir da não-percepção dessa coexistência e inseparabilidade. Nossa racionalização cartesiana admite a complexidade na observação dos fatos. Contudo, é através da experiência prática e a partir do Sujeito $(T)$ na emergência reflexiva sobre ela que podemos reformar o pensamento e unir o que está disjunto (Morin, 2002a).

- $3^{\circ}$ nível de realidade/percepção - terceira distinção:integração dos sistemas - princípio hologrâmico ou hologramático

Compreendemos a integração dos quatro sistemas a partir do princípio hologrâmico, onde a parte está no todo, assim como o todo está 
inscrito nas partes (Morin, 2002a). O trabalhador em saúde, na sua ação, revela sua pertença ao sistema Sujeito/Política Pública - Coletividade no seu fazer profissional, no fazer da equipe ou do serviço. Da mesma forma, nas discussões e proposições da política pública, encontram-se os saberes e conhecimentos advindos dos sujeitos trabalhadores nas suas práticas. Pensamos que, nessa integração, emerge o princípio da incerteza trabalhado por Morin (2002a, p. 126): “Eu falo, mas, quando falo, quem fala? Sou 'Eu' só quem fala? Será que, por intermédio do meu 'eu', é um nós que fala?".

Refletimos sobre a organização da saúde e a saúde da organização, em que Sujeitos previamente organizados por conceitos e lógicas do fazer em saúde, no desafio da integração entre os saberes, realizam ativações recursivas entre desorganizações e novas organizações no processo de atenção integral ao Sujeito usuário. Essa recursividade entrelaça aspectos que organizam o fazer profissional, a equipe, o serviço, a política pública e que produzem e reproduzem aspectos saudáveis e não-saudáveis nesses sistemas.

- 4 nível de realidade/percepção - quarta distinção:a transdialógica

É a nossa leitura/tradução/reconstrução na reintrodução do conhecimento no conhecimento para compreender a integração entre os sistemas Sujeito/Alteridade, Sujeito/Equipe, Sujeito/Serviço e Sujeito/Política Pública, a partir de uma lógica transdisciplinar. O exercício permanente da pesquisadora foi refletir sobre suas lógicas e suas ações, como Sujeito $(T)$, compreendendo que cada um dos Sujeitos $(T)$ participantes também ocupa esse lugar nos seus processos de auto-eco-organização.

\section{Diálogos transdialógicos - desvelando contradições}

Refletimos sobre a dinâmica de organização e/ou desorganização de um Sujeito que, sujeitado a um contexto, seja ele intrapsíquico, interrelacional e/ou inter-institucional, também sujeita o contexto a sua lógica - um sofrimento psíquico, um mal-estar na submissão e dificuldades no diálogo com outras lógicas, seja no fazer individual ou no coletivo. $\mathrm{Na}$ exigência de um olhar a si, ao outro e à coletividade, necessita distinguir as lógicas que "co-operam" num determinado contexto para promover a unidualidade.

No serviço pesquisado, a reunião de equipe, como espaço privilegiado de transversalidades entre a teoria e a prática, acontece semanalmente. Num primeiro momento, realiza-se a organização da reunião, quando são agendados os assuntos gerais e os casos a serem discutidos. Esse é o momento em que a organização do sistema Sujeito/Outro - Equi- 
pe interage e dá voz ao sistema Sujeito/Alteridade na eleição dos assuntos e dos casos a serem discutidos, dinamizando a circularidade entre esses dois e os outros sistemas:Sujeito/Nós - Serviço e Sujeito/Coletividade - Política Pública. Essa dinâmica recursiva e sistêmica tem como organizadores as lógicas da Reforma Psiquiátrica.

A agenda é realizada a partir de necessidades individuais e/ou coletivas que imprimem uma dinâmica nesse processo intersubjetivo e interdisciplinar. Observou-se que, na reunião de equipe no CAPS, há um organizador que é a situação de "urgência" ou não, no atendimento ao usuário, e, como decorrência, surgem os questionamentos quanto aos critérios e procedimentos na atenção. Entretanto, na maioria das vezes, a discussão não resulta em definições ou encaminhamentos quanto à organização do processo de trabalho a partir de uma compreensão complexa e sistêmica.

No contexto da quarta reunião, no processo reflexivo, objetivou-se a reflexão sobre a dinâmica do processo de trabalho, na inclusão dos Sujeitos e suas lógicas, como operadores e "co-operadores" na organização do serviço. A equipe comentou suas dificuldades e avanços na ativação da integralidade no serviço. Aparece na fala dos Sujeitos trabalhadores e nas observações feitas pela pesquisadora que existe muito investimento em direção da ativação da integralidade na atenção ao usuário. Também apareceram divergências entre os participantes quanto aos conceitos do que é um CAPS, quanto a formas de funcionamento do serviço e relacionamentos com a rede de saúde.

Apesar desses investimentos, há diálogos que não se integram na realização e organização das tarefas em virtude dos diferentes conceitos e idéias dos trabalhadores. Existem hiatos entre o Sujeito do discurso e a ação do Sujeito, seja no fazer individual ou no coletivo.

Após esse momento de reflexão, a pesquisadora permaneceu na reunião de equipe, observando que as discussões prosseguiram com os Sujeitos trabalhadores operando suas tarefas pela lógica cartesiana, que não interliga as partes ao todo, ficando "negada" a organização e a interdependência entre os sistemas - assim, cada parte é vista separadamente. Sem organização, não há possibilidade de desenvolver olhares e práticas integrais. $\mathrm{O}$ sistema apresenta pouca mobilidade e relações estereotipadas.

Surgiu, então, um impasse na lógica da pesquisadora, traduzido por estes questionamentos: como explicar a ativação da integralidade e como lidar com a impotência de não encontrar a "cura" para os problemas da equipe? Após essa primeira racionalização, a pesquisadora compreende esta outra contradição em sua computação lógica: estava operando a partir da lógica clássica e olhando para a "doença" da equipe. Utilizando as contradições - "brechas lógicas", enquanto espaço de construção (Morin, 2001, 2002b) -, a pesquisadora desvela a complexidade do contexto. 
Lógica da doença/lógica disciplinar e/ou

lógica da integralidade/lógica transdisciplinar

Observamos que coexistem no contexto do serviço e da equipe duas lógicas em "co-operação". Na bibliografia sobre a reorientação do modelo de atenção à saúde, alude-se às práticas orientadas pela doença, que devem ser modificadas para as práticas integrais. $O$ que fizemos nesta investigação foi traduzir e explicitar alguns elementos das lógicas subjacentes a esses dois modelos.

Compreendemos/explicamos que a ativação da integralidade ocorre no processo de unidualidade entre a lógica disciplinar/lógica da doença e a lógica transdisciplinar/lógica da integralidade na organização do fazer profissional/disciplinar, na organização dos processos de trabalho e na organização da política pública. A primeira é decorrência do paradigma cartesiano. Está diretamente vinculada a uma visão dicotômica do mundo que traz em seu escopo a separação entre Sujeito e objeto e os procedimentos reducionistas que desintegram o todo em várias partes incomunicáveis entre si. A segunda, que exige um processo intersubjetivo e interdisciplinar para a realização de ações transdisciplinares, é decorrência de um paradigma complexo.

Trabalhar em serviços públicos em saúde requer um olhar multidimensional, abertura às contradições e rupturas nas lógicas advindas dos conhecimentos e formações disciplinares. É por meio das interligações entre as partes, no trabalho em redes, na visão psicossocial e coletiva que o trabalhador exercita a mudança de seu fazer profissional no trabalho em equipes. Paradoxalmente, aí é que se encontram seus maiores desafios.

As situações oriundas dessa "co-operação" entre duas lógicas antagônicas, contraditórias, concorrentes e complementares geram dissonâncias e desencontros entre os trabalhadores e suas práticas. Há sofrimentos pela incomunicabilidade entre Sujeitos e pela própria inconsciência em face dessa incomunicabilidade, pela não-percepção da disjunção e contradição entre conceitos e idéias não referenciados a seus contextos.

O que parece angustiante no cotidiano dos trabalhadores é que mesmo aqueles que já aceitam a complexidade e exercitam o pertencimento aos sistemas oscilam entre as possibilidades de criação e instituição de práticas integrais e a reprodução do modelo da doença. Existem limitações no trabalho coletivo pelas diferenças entre as lógicas e pela impossibilidade de o trabalhador ocupar o seu lugar egocêntrico quando está identificado com o"eu" sujeito objetivado. Ou seja, na identificação com o doente e com a doença, a equipe também adoece.

Compreendemos que a reforma de pensamento e as mudanças nas organizações dos processos de trabalho estão submetidas a um proces- 
so de abertura para a emergência reflexiva que produz estremecimentos nas lógicas e conhecimentos estruturados numa lógica disciplinar. Esta tem como "conhecido" um produto final que, por vezes, é o próprio adoecimento do trabalhador quando este não ultrapassa a percepção do "erro" e nem reconhece as contradições.

No serviço pesquisado, evidenciaram-se, em diversos momentos, fatos e acontecimentos que corroboram as práticas orientadas pelas duas lógicas em uma dinâmica inseparável. As contradições emergiram entre as falas e as ações dos trabalhadores:"não existe diferença entre o psicólogo, o fonoaudiólogo, a pedagoga, a assistente social, o médico"; "enquanto colega, não se procura fazer distinção entre as categorias... embora a coisa fique, assim, um pouco centrada na psiquiatria"; "a gente estudou assim, aprendeu a trabalhar assim e o ponto de partida é o psiquiatra"; "toda semana tinha material para ler, de repente a gente estava atendendo só crônicos, todos nós, foi uma mentalidade que a gente desenvolveu enquanto CAPS",'eu discordo de que esta equipe tem ainda aquela figura do psiquiatra como um saber que define";"eu me referi às situações de urgência ... porque a psiquiatra está com a agenda cheia, não dá pra esperar até sexta" (Diário de campo - 4a reunião de equipe).

Houve a defesa de que a relação entre os profissionais não está associada ao lugar que cada um ocupa no sistema; entretanto, no fazer coletivo, o organizador do processo e do serviço geralmente é a doença. Nos casos de urgências, o usuário é escutado e a consulta psiquiátrica é agendada, sendo que o usuário a aguarda em casa. Assim, o psiquiatra é colocado numa posição de saber/poder, pois, no imaginário dos trabaIhadores, é quem detém um saber sobre a loucura/cura e o controle dos riscos, seja ao usuário, seja ao profissional.

$A$ reprodução da lógica reducionista ( $A$ é $A, A$ não é não- $A$ ) aparece como uma dificuldade apresentada pela equipe na ativação da integralidade, não havendo a possibilidade de encontro entre trabalhador/trabalhador e/ou trabalhador/usuário. Um ocupa o lugar de sujeito; o outro, o lugar de objeto, juntamente com os protótipos e estereótipos dessas relações. A identificação e/ou a distinção ocorre pela doença em que profissional é profissional, louco é louco -; então, logicamente, profissional não é louco. Não defendemos a banalização do adoecimento psíquico, mas a aproximação entre as fronteiras pela inclusão de um Terceiro Termo que seja, ao mesmo tempo, profissional e louco. Pensamos que essas dificuldades remetem à necessidade de os Sujeitos e os grupos manterem-se fechados para lógicas que ameaçam sua identidade como sistemas (Seminotti, Borges, \& Cruz, 2006).

Existe também um comportamento que subtrai a possibilidade do diálogo entre as lógicas expressadas pelos Sujeitos nas ações de suas especialidades/afazeres técnicos, que é o não reconhecimento das distintas formações disciplinares. Um receio do fechamento nas "gaiolas dis- 
ciplinares" (D'Ambrosio, 1997). Entretanto, é a partir desse conhecimento que o profissional pode interdisciplinarizar. Evita-se a reprodução de modelos rígidos e estereotipados (manicomiais); contudo, tangencia-se o não-cuidado pela inconsciência e reprodução das lógicas que o produziram. Aqui se ancoram algumas críticas da contra-reforma.

Observamos que a ambigüidade atual entre a lógica cartesiana e a complexa nos serviços de saúde mental está representada pela discussão entre o ambulatório e o CAPS. Essa distinção não está na nomenclatura dos serviços, mas sim na organização dos processos de trabalho. Dito de outra forma: pode haver equipes trabalhando a partir de uma visão psicossocial no ambulatório e, num CAPS, com um modelo mais individualizado, sem integrar as condições sociais nos atendimentos aos usuários e com posturas fragmentadoras e excludentes.

Concomitantemente, os trabalhadores exercitam movimentos recursivos na busca do atendimento integral e psicossocial. Esse fazer é intenso e sistemático, orientado por uma vontade responsável no tratamento humanizado. É uma tarefa hercúlea, pois esse caminho é trilhado em sua própria subjetividade. É um Sujeito que, em sua circularidade dinâmica, institui seus sistemas de referência e não-referência.

Relacionamos também, como resultados da pesquisa, as rupturas/ integrações lógicas na computação cognitiva da pesquisadora:

- inseparabilidade dinâmica entre a lógica disciplinar e a transdisciplinar - práticas estruturadas numa lógica clássica coexistem com práticas estruturadas numa lógica transdisciplinar no fazer individual e/ou coletivo, na unidualidade;

- inseparabilidade dinâmica do sistema Sujeito/Alteridade em relação aos demais sistemas: na análise dos dados, após a distinção dos sistemas, na identificação de cada um, não foi possível separar o sistema Sujeito dos demais;

- inseparabilidade dinâmica entre pesquisadora e Sujeitos participantes da pesquisa: a concepção da pesquisadora enquanto observador/conceptor/ator/observado possibilitou a identificação e a distinção com os trabalhadores, seja como participante, trabalhadora, gestora ou pesquisadora, isto é, pelo lugar que ocupou no sistema;

- inseparabilidade dinâmica entre Atenção e Gestão: fica reafirmada a unidualidade entre atenção e gestão pela recursividade auto-ecoorganizadora do sistema, onde o Sujeito institui práticas e é subjetivado pela política pública;

- Inseparabilidade dinâmica entre Sujeito e o Grupo; entre o Sujeito e a Coletividade: ao preparar a pesquisa, a pesquisadora oscilou, no aprofundamento da noção de Sujeito e na lógica transdisciplinar, entre conceitos e noções sobre o Sujeito e sobre os processos grupais. Quando o Sujeito passou a apresentar-se como uma questão de maior relevância, apareceram questionamentos: pode ser esta pesquisa concreti- 
zada com os Sujeitos e não com o grupo? Esse grupo existe? Essa contradição expressou-se na pesquisadora pela reprodução da lógica cartesiana que insiste em polarizar os pares de contraditórios - ora o valor está no Sujeito, ora no grupo/coletivo, revelando-se uma cegueira paradigmática em relação aos diferentes níveis de realidade e à consideração do Terceiro Termo Incluído. Essa contradição foi ultrapassada pela compreensão entre a recursividade organizacional entre Sujeito e o grupo/Sujeito e coletividade;

- inseparabilidade dinâmica entre intersubjetividade e afetividade: pela compreensão intersubjetiva, há um reconhecimento no outro e pelo outro; a pesquisadora pode reconhecer-se na equipe e na pesquisa pela circularidade de afetos entre todos os Sujeitos participantes.

A partir dessa percepção de inseparabilidade, a pesquisadora compreende/explica que a distinção entre Sujeito subjetivo (Eu) e sujeito objetivado (eu) acontece na ação e pelo lugar que cada um ocupa no sistema. Na equipe reflexiva, os trabalhadores necessitam olhar para os processos intersubjetivos entre si, pois é na ação de atender ao usuário e de trabalhar coletivamente que podem perceber suas contradições e seus afetos. Principalmente aqueles ligados à xenofobia e ao etnocentrismo.

Também é possível explicarmos para compreendermos que a integralidade organiza a ação transdisciplinar nas equipes multiprofissionais na saúde coletiva e que, recursivamente, a transdisciplinaridade promove a integralidade e exige que os trabalhadores se subjetivem enquanto Sujeitos ( $T$ ).

$\mathrm{E}$, sem nos furtarmos à teleologia, entendemos que, através do Sujeito $(T)$, existe a possibilidade de compor novas integrações lógicas. A pesquisadora enquanto Sujeito $(T)$ também atuou como mediadora on-line, exercendo a reflexão na ação do aqui e agora, que possibilitou questionamentos sobre a organização centrada na doença junto à equipe.

Pensamos que os estudos sobre os processos de grupo podem contribuir para o entendimento de que o trabalho na Equipe Reflexiva, na ação individual e/ou coletiva, possa ser um espaço de construção de processos e tecnologias transdialógicas na ativação da integralidade.Vários estudiosos grupalistas e dos processos de integração entre os saberes tangenciaram a idéia de que o grupo pode ser um dispositivo de interligação entre o Sujeito e a Coletividade. Precisamos desenvolver estratégias que mobilizem os trabalhadores na constituição dos grupos de trabalho, delimitando objetivos comuns e refletindo sobre as lógicas subjacentes à tarefa a ser realizada (Azevedo e Souza et al., 2006; Fazenda, 2002; Japiassu, 1976).

Assim, compreendemos que os aspectos facilitadores da ativação da integralidade nas equipes multiprofissionais na saúde coletiva são os 
processos de reflexão transdialógica dos trabalhadores sobre a organização das práticas e dos serviços, processos estes que possibilitam interações saudáveis ao trabalhador e ao usuário e a reinvenção do cotidiano pela coletividade. Os aspectos dificultadores dessa questão são aqueles que suprimem os Sujeitos e a intersubjetividade nas relações entre trabalhadores e trabalhadores/usuários; e que não traduzem o pensamento sistêmico, do contexto e do complexo.

A compreensão da ativação da integralidade, mote inicial deste estudo, é um grande desafio posto aos trabalhadores. Além das dificuldades de aplicação prática dessa diretriz no cotidiano dos serviços, evidencia-se que ela está interligada com as questões de gestão da política pública e que delas é interdependente. Entretanto, por uma falta de entendimento sistêmico do SUS, muitas cobranças e grande parcela de responsabilização recaem sobre os trabalhadores, que, em muitos momentos, estão cerceados em suas práticas por dificuldades administrativas, de recursos humanos, infra-estrutura e de uma rede de cuidados.

A temática pesquisada é assunto complexo e contextualizado. $O$ trabalho em equipes é uma realidade neste momento de reorientação do modelo assistencial à saúde como um dispositivo de integração dos diversos saberes existentes nos serviços e desenvolvimento de tecnologias na realização de tarefas. Esse trabalho coletivo também se encontra afinado com a proposta da saúde em que os processos de saúde/doença/cuidado são compreendidos na interligação com as condições sócio-ambientais dos Sujeitos, exigindo olhares multidimensionais e multirreferenciais de diversos profissionais.

\title{
The subject and the collectivity - the transdialogical way in collective health.
}

\begin{abstract}
This paper presents the results and reflections of a research carried out with the aim of understanding both hindering and facilitating aspects of the process of activation of comprehensiveness in the transdisciplinary action in a multi-professional team in collective health. This transdialogical trajectory has been based on the theory of complexity and principles of the method by Edgar Morin, and the transdisciplinary logic proposed by Basarab Nicolescu, having as its central axis the interdependence between Subject and Collectivity in the construction of health public policy. The research has showed the coexistence of two logics organizing the work processes in health: the logic of illness/disciplinarity, and the logic of comprehensiveness/transdisciplinarity.
\end{abstract}

Keywords: Public health. Transdisciplinarity. Collective behavior. Psychiatric reform. Health professionals. 
The subject and the collectivity - the transdialogical way in collective health.

Resumen: L'article suivant présente les résultats d'une recherche réalisée dans le but de comprendre aussi bien les aspects qui difficultent que ceux qui facilitent le processus d'activation de l'intégralité dans l'action transdisciplinaire au sein d'une équipe multiprofessionnelle en santé collective. Ce parcours trans-dialogique est fondé sur la théorie de la complexité et les principes de la méthode d'Edgar Morin ainsi que la logique transdisciplinaire proposée par Basarab Nicolescu, ayant comme organisateur central l'interdépendance entre Sujet et Collectivité dans la construction de la politique publique de la santé. La recherche suggère l'éveil de la coexistence de deux logiques qui organisent les processus de travail dans le secteur de la santé: la logique de la maladie / logique disciplinaire et la logique de l'intégralité / logique transdisciplinaire.

Mots-clés: Santé mentale. Transdisciplinaires. Comportement collectif. Réforme psychiatrique, Professionnels de santé.

\section{The subject and the collectivity - the transdialogical way in collective health.}

Resumen: Este artículo presenta los resultados y reflexiones de una investigación que se realizó con el objetivo de comprender aspectos dificultadores y facilitadores en el proceso de activación de la integralidad en la acción interdisciplinaria en un equipo multiprofesional en salud colectiva. El camino transdialógico utilizó como fundamentos la teoría de la complejidad y los principios del método de Edgar Morin y la lógica transdisciplinar propuesta por Basarab Nicolescu, que tiene como organizador central la interdependencia entre Sujeto y Colectividad en la construcción de la política pública en salud. La investigación trajo el desvelamiento de la coexistencia de dos lógicas que organizan los procesos laborales en salud: la lógica de la enfermedad/lógica disciplinar y la lógica de la integralidad/lógica transdisciplinar.

Palabras-clave: Salud pública.Transdisciplinaridad. Conducta colectiva. Reforma Psiquiátrica. Profesionales de la salud.

\section{Referências}

Almeida Filho, N. (1997). Transdisciplinaridade e saúde coletiva. Ciência e Saúde Coletiva, 11(1/2), 5-20.

Anguera, M.T., Arnau, J., Ato, M., Rosario, M., Pascual, J., \& Vallejo, G. (1995). Métodos de investigación en psicología. Madrid: Editorial Síntesis.

Ayres, J. R. C. M. (2001). Sujeito, intersubjetividade e práticas de saúde. Ciência e Saúde Coletiva, 6(1), 63-72.

Azevedo e Souza, V. B., Azevedo e Souza, R., \& Marques, C. P. (2006). Interdisciplinaridade/transdisciplinaridade: uma relação dialógica de 
autonomia/ dependência. In B. Hackmann \& N. R. Stein (Orgs.), Reflexões sobre a formação de professores (pp. 26-35). Taquara, RS: FACCAT.

Badescu, H., \& Nicolescu, B. (Orgs.). (2001). Stéphane Lupasco: o homem e a obra. São Paulo:TRIOM.

Barker, J. R., \& Domenici, K. L. (1999). Práticas de mediação para equipes baseadas em conhecimento. In D. F. Schnitamn \& S. Littlejohn, S., Novos paradigmas em mediação (pp. 329-356). Porto Alegre: ArtMed.

Campos, G. W. S. (1997a). Considerações sobre a arte e a ciência da mudança: revolução das coisas e reforma das pessoas. O caso da saúde. In L. C. O. Cecílio (Org.), Inventando a mudança na saúde (pp. 29-87). São Paulo: Hucitec.

Campos, G.W.S. (1997b). Subjetividade e administração de pessoal:considerações sobre modos de gerenciar o trabalho em equipes de saúde. In E. E. Merhy \& R. Onocko (Orgs.), Agir em saúde: um desafio para o público. São Paulo: Hucitec.

Campos, G. W. S. (1998). O anti-Taylor: sobre a invenção de um método para co-governar instituições de saúde produzindo liberdade e compromisso. Cadernos de Saúde Pública, 14(4), 863-870.

Campos, G.W.S. (2000). Saúde pública e saúde coletiva: campo e núcleo de saberes e práticas. Ciência e Saúde Coletiva, 5(2), 219-230.

Ceccim, R. B. (2005). Educação permanente em saúde: descentralização e disseminação de capacidade pedagógica na saúde. Ciência e Saúde Coletiva, 10(4), 975-986.

Cecílio, L. C. O. (Org.). (1997a). Inventando a mudança na saúde (2a ed.). São Paulo: Hucitec.

Cecílio, L.C.O. (1997b). Modelos tecno-assistenciais em saúde: da pirâmide ao círculo, uma possibilidade a ser explorada. Cadernos de Saúde Pública, 13(3), 469-478.

Cecílio, L. C. O. (2001). As necessidades de saúde como conceito estruturante na luta pela integralidade e eqüidade na atenção em saúde. In R. Pinheiro \& R. A. Mattos (Orgs.), Os sentidos da integralidade na atenção e no cuidado à saúde (pp. 113-126). Rio de Janeiro: Instituto de Medicina Social, Universidade do Estado do Rio de Janeiro.

Coelho, M.T. A. D., \& Almeida Filho, N. (2002). Conceitos de saúde em discursos contemporâneos de referência científica. História, Ciência, Saúde, 9(2), 315-333.

D'ambrosio, U. (1997). Transdisciplinaridade. São Paulo: Palas Athena. 
Fagundes, S. (2003).Psicologia a serviço da integralidade [Entrevista]. Jornal Entre Linhas. Recuperado em 10 de setembro de 2003, de http:// www.crp07.org.br/entrevista.php?id=3

Fagundes, S. (2006). Águas da pedagogia da implicação: intercessões da educação para políticas públicas de saúde. Porto Alegre: UFRGS.

Fazenda,I.C. A. (2002). Interdisciplinaridade: história, teoria e pesquisa (10a ed.). Campinas, SP: Papirus.

Feuerwerker, L. (2005). Modelos tecno-assistenciais, gestão e organização do trabalho em saúde: nada é indiferente no processo de luta para a consolidação do SUS. Interface, 9(18), 489-506.

Gallo, E., Luchesi, G., Machado Filho, N., \& Ribeiro, P.T. (1998). Reforma sanitária:uma análise de viabilidade. Cadernos de Saúde Pública, 4(4),414419.

Iribarry, I. N. (2003). Aproximações sobre a transdisciplinaridade: algumas linhas históricas, fundamentos e princípios aplicados ao trabalho de equipe. Psicologia: Reflexão e Crítica, 16(3), 483-490.

Jantsch, A. P., \& Bianchetti, L. (2002). Interdisciplinaridade: para além da filosofia do sujeito. Petrópolis, RJ:Vozes.

Japiassu, H. (1976). Interdisciplinaridade e a patologia do saber. Rio de Janeiro: Imago.

L'Abbate, S. (1997). Comunicação e educação: uma prática de saúde. In E. E. Merhy \& R. Onocko, Práxis em salud: um desafio para lo público. Buenos Aires: Lugar Editorial.

L'Abbate, S. (2003). A análise institucional e a saúde coletiva. Ciência e Saúde Coletiva, 8(1), 265-274.

Lana, F. C. F., \& Gomes, E. L. R. (1996). Reflexões sobre o planejamento em saúde e o processo da reforma sanitária brasileira. Revista Latino-Americana de Enfermagem, 4(1), 97-110.

Mattos, R. A. (2001). Os sentidos da integralidade:algumas reflexões acerca de valores que merecem ser defendidos. In R.Pinheiro \& R. A. Mattos (Orgs.), Os sentidos da integralidade na atenção e no cuidado à saúde (pp.39-64). Rio de Janeiro: Instituto de Medicina Social.

Mattos, R. A. (2004). A integralidade na prática (ou sobre a prática da integralidade). Cadernos de Saúde Pública, 20(5); 1411-1416.

Merhy, E. E. (1997). Em busca da qualidade dos serviços de saúde: os serviços de porta aberta para a saúde e o modelo tecno-assistencial em defesa da vida. In L.C.O. Cecilio (Org.), Inventando a mudança na saúde (2a ed.). São Paulo: Hucitec. 
Minayo, M.C.S. (2001). Estrutura e sujeito, determinismo e protagonismo histórico:uma reflexão sobre a práxis da saúde coletiva. Ciência e Saúde Coletiva, 6(1), 7-19.

Ministério da Saúde. Secretaria de Atenção a Saúde. Departamento de Ações Programáticas. (2004). Saúde mental no SUS: os centros de atenção psicossocial. Brasília, DF: Autor.

Moraes, M. C. (2004). Pensamento eco-sistêmico: educação, aprendizagem e cidadania no século XXI. Petrópolis, RJ: Vozes.

Morin, E. (2000). A inteligência da complexidade (2a ed.). São Paulo: Petrópolis.

Morin, E. (2001). Ciência com consciência (5a ed.). Rio de Janeiro: Bertrand Brasil.

Morin, E. (2002a). A cabeça bem-feita: repensar a reforma, reformar o pensamento (6a ed.). Rio de Janeiro: Bertrand Brasil.

Morin, E. (2002b). O método 2: a vida da vida. Porto Alegre: Sulina.

Morin, E. (2002c). Os sete saberes necessários à educação do futuro (5a ed.). São Paulo: Cortez.

Morin, E. (2003). O pensamento complexo (4a ed.). Lisboa: Instituto Piaget.

Morin, E. (2005a). O método 1: a natureza da natureza. Porto Alegre: Sulina.

Morin, E. (2005b). O método 3: o conhecimento do conhecimento. Porto Alegre: Sulina.

Nicolescu, B. (2001).O manifesto da transdisciplinaridade (2a ed.).São Paulo: TRIOM.

Nicolescu, B. (2002). Fundamentos metodológicos para o estudo transcultural e transreligioso. In Encontro Catalisador do Projeto "A Evolução Transdisci-plinar na Educação". Educação e Transdisciplinaridade II - CETRANS. São Paulo:TRIOM.

Nicolescu, B. (2005). Transdisciplinarity: Past, present and future. Congresso Mundial de Transdisciplinaridade. Vitória, Espírito Santo.CD-ROM

Paim, J. S., \& Almeida Filho, N. (1998). Saúde coletiva: uma "nova saúde pública" ou campo aberto a novos paradigmas? Revista de Saúde Pública, 32(4), 299-316.

Paim, J.S., \& Almeida Filho, N. (2000). A crise da Saúde Pública e a utopia da Saúde Coletiva. Salvador: Casa da Qualidade.

Paim, J.S., \& Teixeira, C. F. (2006). Política, planejamento e gestão em saúde: balanço do estado da arte. Revista de Saúde Pública, 40(número especial), 73-78. 
Passos, E., \& Barros, R. B. (2000). A construção do plano da clínica e o conceito de transdisciplinaridade. Psicologia: Teoria e Pesquisa, 16(1), 71-79.

Peduzzi, M. (1998). Equipe multiprofissional de saúde: a interface entre trabalho e interação. Tese de Doutorado, Universidade Estadual de Campinas, Campinas, SP.

Peduzzi, M. (2001). Equipe multiprofissional em saúde: conceito e tipologia. Revista de Saúde Pública, 1(35), 103-109.

Peduzzi, M., \& Amselmi, M. L. (2002). O processo de trabalho de enfermagem: a cisão entre planejamento e execução do cuidados. Revista Brasileira de Enfermagem, Brasília, 55(4), 392-398.

Pinheiro, R., \& Luz, M. (2003). Práticas eficazes x modelos ideais: ação e pensamento na construção da integralidade. In R. Pinheiro \& R. A. Mattos (Org.), Construção da integralidade: cotidiano, saberes e práticas em saúde (pp. 7-34). Rio de Janeiro: UERJ.

Pinheiro, R., \& Mattos, R. A. (2004). Cuidado: as fronteiras da integralidade. Rio de Janeiro: Hucitec.

Pitta, A.M. F. (2001). Reorientação do modelo de atenção: equidade e justiça social na organização de serviços de saúde mental. In P.G. Delgado (Org.), Cadernos de Textos: III Conferência Nacional de Saúde Mental (pp. 16-23). Brasília: Ministério da Saúde.

Pombo, O. (2005). Interdisciplinaridade e integração dos saberes.Liinc em Revista, 1(1), 4-16.

Ribeiro, E. C. O., \& Motta, J. I. J. (1996). Educação permanente como estratégia na reorganização dos serviços de saúde. Revista Divulgação em Saúde para o Debate, (12), 39-44.

Sá, M. C. (2001). Subjetividade e projetos coletivos: mal-estar e governabilidade nas organizações de saúde. Ciência e Saúde Coleti$v a, 6(1), 151-164$.

Schraiber, L. B., \& Machado, M. H. (1997). Trabalhadores da saúde: uma nova agenda de estudos sobre recursos humanos em saúde no Brasil. In S. M. F. Teixeira (Org.), Saúde e democracia: a luta do CEBES (pp. 281-298). São Paulo: Lemos.

Schraiber, L. B., Peduzzi, M., Nemes, M. I. B., Castanheira, E. R. L., \& Kon, R. (1999). Planejamento, gestão e avaliação em saúde:identificando problemas. Ciência e Saúde Coletiva, 4(2), 221-242.

Seminotti, N. (2000). La organización y dinámica del grupo psicológico: la multiplicidad/diversidad de organizadores del grupo. Tesis Doctoral, Facultad Psicología, Universidad Antónoma de Madrid, Madrid. 
Seminotti, N., Borges, B., \& Cruz, J. (2004). Pequeno grupo como organizador do ambiente de aprendizagem. Psico USF, 9(2), 181-189.

Seminotti, N., Scarparo, H. B. K., Moraes, M. L. A., \& Alves, M. (2006). Olhando e vivendo grupos - reflexões sobre uma prática. Psicologia Argumentos, 24(45), 73-80.

Sommermann, A. (2006). Inter ou transdisciplinaridade? Da fragmentação disciplinar ao novo diálogo entre os saberes. São Paulo: Paulus.

Testa, M. (2004). Pensar en salud. Buenos Aires: Lugar.

Vasconcelos, M. J. E. (2002). Pensamento sistêmico: o novo paradigma da ciência. Campinas, SP: Papirus.

Recebido em: 24/05/2007

Aceito em: 24/09/2007 